\title{
La importancia de la alfabetidad visual en la enseñanza del derecho a personas con discapacidad intelectual: una intervención pedagógica
}

\begin{abstract}
Resumen
Este artículo pretende fundamentar teórica y empíricamente la necesidad de incluir en los programas de estudios y en el currículum de formación docente los contenidos que preparan a los profesores para enseñar derecho a través de las artes visuales y la alfabetidad visual. En primer lugar, se describe e ilustra la utilización metodológica de recursos visuales a través de una investigación socioeducativa reciente basada en la experiencia de la enseñanza de Derechos Fundamentales en el marco del Título de "Asistente Jurídico para personas con discapacidad intelectual" de la Universidad Rey Juan Carlos. En segundo lugar, se resumen algunas de las experiencias educativas relacionadas con las artes visuales y se da a conocer la metodología utilizada según la pedagogía del arte, en la asignatura de "Introducción al Derecho". En tercer y último lugar, se exponen los principales resultados y las competencias adquiridas por los participantes en materia jurídica, en virtud de las experiencias educativas de alfabetización visual en el aula, y su papel para crear relatos de los derechos desde dentro. Se concluye subrayando la importancia de implementar este tipo de intervenciones pedagógicas, que han de servir para la definición, formulación e implementación de una política pública que realmente tenga en cuenta cómo se sienten las personas con discapacidad intelectual ante las diferentes barreras sociales, dotándoles de voz, sentido y visibilidad.
\end{abstract}

\author{
Delia Manzanero \\ Doctorado en Filosofía. \\ Profesora, Universidad Rey Juan \\ Carlos de Madrid, Madrid, España. \\ Correo electrónico: \\ delia.manzanero@urjc.es \\ ๑1 orcid.org/0000-0002-6895-1254 \\ Google Scholar
}

Recibido: marzo 17 de 2021

Aprobado: junio 23 de 2021

Key words:

alfabetidad visual, educación, derecho, pedagogía, arte.

\footnotetext{
* Este estudio se ha realizado en el marco del proyecto de innovación docente: “Discapacidad: Una cuestión de derecho", financiado por la Oficina de Derechos Humanos de la URJC durante el periodo (2019-2020), cuya investigadora principal es Marta Albert Márquez. Dicho proyecto tiene continuidad en el Título universitario de "Asistente Jurídico para personas con discapacidad intelectual" que se ha ofertado de manera pionera el año académico 2020-2021 en la Universidad Rey Juan Carlos de España.
} 


\section{The importance of visual literacy in teaching the Law to people with intellectual disabilities: a pedagogical intervention}

\begin{abstract}
This article aims to provide a theoretical and empirical foundation for the need to include in the study programs and in the teacher training curriculum the contents that prepare teachers to teach Law through visual arts and visual literacy. In the first place, the methodological use of visual resources is described and illustrated through recent socio-educational research based on the experience of teaching Fundamental Rights within the framework of the Title of "Legal Assistant for people with intellectual disabilities" of Universidad Rey Juan Carlos. Second, some of the educational experiences related to the visual arts are summarized and the methodology used according to the pedagogy of art in the subject "Introduction to Law" is presented. Third and last, the main results and the competences acquired by the participants in legal matters are presented, by virtue of the educational experiences of visual literacy in the classroom and their role in creating stories of their rights from within. The article concludes by underlining the importance of implementing this type of pedagogical interventions which must serve for the definition, formulation and implementation of a public policy that really takes into account the way in which people with intellectual disabilities feel in the face of different social barriers, giving them voice, meaning and visibility.
\end{abstract}

Key words:

visual literacy, education, Law, pedagogy, art. 


\section{Introducción}

La educación del siglo XXI viene caracterizada por el carácter aplastantemente visual de la experiencia del aprendizaje. Sea instintiva o intelectualmente, gran parte de nuestro proceso de aprendizaje es visual y, según nos recuerda la diseñadora y profesora Donis A. Dondis (2017) en La sintaxis de la imagen, este "input visual tiene una gran importancia para el entendimiento y la supervivencia" (p. 84). Este aspecto cobra aún más relieve hoy en día, en que la masiva producción cotidiana de imágenes y la proliferación de prácticas visuales muestran la importancia que las imágenes y los imaginarios tienen en las sociedades contemporáneas pues, al fin y al cabo, "todos nosotros somos la cámara primigenia" (Dondis, 2017, p. 85). Gran parte de nuestro presente y la mayor parte del futuro la conformará una generación condicionada por internet, el cine, la fotografía, la televisión, etc., donde las cámaras y el computador visual serán un medio auxiliar, una prolongación más de nuestros recursos naturales de captación de la realidad y de comunicación. Este fenómeno de expansión de lo visual a las diversas fases del aprendizaje ha ido marcando también la evolución de nuestros modelos pedagógicos, pero esta comunicación visual y artística no es algo privativo de nuestras sociedades actuales; tales inquietudes pueden remontarse a la experiencia de pueblos primitivos y a la experiencia del aprendizaje que se da en los propios niños, dando como resultado notables modelos pedagógicos que han sabido explorar la riqueza de la alfabetidad visual.

En el caso de España, destaca el uso del arte y de la sección cinematográfica en las Misiones Pedagógicas, en el marco de las consideraciones de los institucionistas, quienes creían que parte de la vulgaridad espiritual de su entorno se debía a esa relación educativa tradicional, con su predominante pasividad y su falta de contacto con la vida, un planteamiento que quisieron invertir con la Institución Libre de Enseñanza, donde se puso en práctica, 
quizá por primera vez en España, una pedagogía activa que estuvo en íntimo contacto con la vida y con el arte: la pedagogía de la intuición, en la expresión acuñada por Pestalozzi y Fröbel, con un especial énfasis en la educación de la sensibilidad (música, pintura, arte en general) y con el estímulo de las habilidades manuales (dibujo, carpintería, jardinería,...). Este método intuitivo es retomado y enriquecido gracias a la obra del genio educador, Manuel Bartolomé Cossío (1906), cuya pedagogía entendida como arte complementa muy bien la teoría de la alfabetidad visual.

Lo que propone Cossío es una defensa de la educación como arte de "saber ver", la cual no solo respondía al temperamento artístico de Cossío, sino que además era una justa reacción contra una enseñanza intelectualista y esclerotizada, basada en el exclusivo aprendizaje memorístico, que era lo que imperaba en la escuela tradicional en nuestro país. Por eso, decía Cossío (1906), "lo urgente hoy en el mundo es evitar otro espectáculo aún más triste: el de los jóvenes que llegan a las aulas universitarias sin saber oír, ni leer, ni pensar, ni decir lo que piensan" (p. 47). En efecto, no solo hay estudiantes que apenas piensan, sino que los que son capaces de hacerlo, a veces no saben expresarlo; para salir al paso de semejante situación hay que romper la rutina acumulada a través de siglos y enseñar a ver, a saber ver, a pensar sobre lo que se ve, apropiándonoslo y asimilándolo a la ley de desarrollo de la propia personalidad. La conclusión a que nos Ilevan todos estos planteamientos es que la educación debe conducirnos a hacer de nosotros mismos nuestra propia obra de arte. Aquí vemos cómo la pedagogía de Cossío, entendida como arte, afirma que debemos dar un paso del mirar al ver, que es el paso que da el maestro cuando en vez de limitarse a instruir se dedica a educar.

Según el método intuitivo, solo es posible la educación mediante el contenido directo con la realidad plenaria y viva del mundo. Resulta en este punto interesante recordar la sentencia de Cossío (1966) de que: "Hay que 
Educar antes que instruir, hacer del niño, en vez de un almacén, un campo cultivable y de cada cosa una semilla y un instrumento para su cultivo" (p. 13). Esto podría verse como un cierto desprecio a los libros, pero en realidad tiene su base en el mal uso que con frecuencia se hacía de ellos cuando se los utilizaba como una forma de suplantación de la realidad, que incapacita al niño para el desarrollo de su propia visión. Por eso, dice Cossío, solo el que es capaz de ver llega a conocer, y "sólo quien es capaz de ver personalmente algo, puede decir en verdad que lo ha comprendido. De nada sirve el 'saber' pacientemente acumulado, si no va acompañado de una visión que revele su significación y su sentido" (Otero, 1994, p. 131).

A tal efecto, nos interesa señalar la necesidad de expandir la educación hacia este nuevo ámbito, de explorar de manera reflexiva nuevos recursos y metodologías dirigidas a desarrollar procesos de alfabetización visual para entender críticamente el alcance de estos métodos pedagógicos. En particular, nos gustaría explorar la utilización de estrategias visuales (dibujos, fotografía, vídeo) como un recurso metodológico especialmente adecuado para aquellas personas que, por distintas razones, no tienen un nivel lingüístico comunicativo desarrollado, como es el caso de algunas personas con discapacidad intelectual (en adelante DI). En la actualidad, son muchos los niños y los jóvenes con DI que experimentan barreras de participación, de exclusión y de segregación durante su proceso de escolarización, y que son abocados posteriormente a otro muro de limitación en el ámbito universitario, enfrentándose desde la infancia al rechazo social, al fracaso y a experiencias negativas que los desvalorizan y frustran. Las bajas expectativas sociales y los condicionamientos culturales - como los presentes en países que tienen la discriminación, la ignorancia, la indiferencia y la intolerancia como atributos inescindibles de su estructura ideológica-, y los prejuicios sociales hacia la persona con discapacidad, representan el punto de partida de un círculo vicioso que limita significativamente sus posibilidades, y que le hace caer 
fácilmente en la falta de autoestima y en la desesperanza de creer que es imposible conseguir un empleo (Suriá et al., 2016, p. 2570). Ello ha motivado a reorganizar nuevos procesos de enseñanza y de aprendizaje orientados a este colectivo, para reducir la exclusión en y desde la educación. Esto supone cambios y modificaciones estructurales en el contenido, accesos y estrategias docentes, e introducir una visión de responsabilidad y compromiso social con el fin de educar en la diversidad, el respeto y la valoración de la autonomía individual de los propios educandos.

Afortunadamente, hoy en día se ha operado un cambio importante de paradigma. Hay una apuesta decidida por romper radicalmente con el modelo paternalista y asistencial, y con la perspectiva médica-rehabilitadora de la función de la escuela, la prisión o los hospitales psiquiátricos, que ciertamente no buscan excluir a los marginales o reforzar la marginalidad (como sucedía en el siglo XVIII), sino que lo que operan es una suerte de secuestro, como lo define certeramente Michael Foucault (1996), "una inclusión por exclusión" (p. 119), cuya finalidad es una suerte de inclusión forzada a través de aparatos de corrección y normalización de los sujetos, que solo habría logrado acentuar la dependencia, aislamiento y exclusión social de las personas con DI.

En su lugar, se ha hecho una clara apuesta por el moderno modelo social de dignidad promovido por la Convención de Naciones Unidas que garantiza los derechos y libertades de las personas con DI; un nuevo modelo que afirma que las personas con discapacidad son sujetos morales que deben disfrutar del pleno ejercicio de sus derechos fundamentales en orden a elegir su propio camino y tomar, en libertad, aquellas decisiones que consideren oportunas sobre las cuestiones que les conciernan, porque eso es precisamente la dignidad, "la dignidad es el recuerdo permanente de que la persona humana es el centro del derecho" (Belda, 2019, p. 254). Esto hace que hoy en día, hablar de discapacidad no implique "centrarse en la limitación individual 
o deficiencia, sino en el desajuste del entorno social hacia la persona y sus necesidades" (Espín y Mera, 2019, p. 42).

Este promisorio modelo de trabajo ha representado para los docentes implicados en este proyecto una oportunidad de mejora y de innovación en nuestra actividad educativa, una oportunidad para buscar alternativas y nuevas formas de actuación pedagógica.

Por eso consideramos de gran relevancia la existencia de este tipo de proyectos de innovación educativa, en muestras como la que vamos a presentar a continuación, por su labor en la sensibilización y concientización sobre las necesidades de apoyo educativo de las personas con DI con base en la alfabetidad visual, pues consideramos que muchas de las barreras presentes en este contexto se deben, en gran medida, a la falta de preparación o conciencia de la opinión pública y de los poderes públicos en la comprensión genérica o particular de las necesidades específicas de la discapacidad.

\section{Metodología: Experiencias educativas de alfabetización visual en el aula}

Las prácticas pedagógicas que se describen a continuación pertenecen a un estudio realizado desde el enfoque de la enseñanza de los derechos humanos, en el marco de la asignatura de "Introducción al Derecho" del Título de Asistente Jurídico de la Universidad Rey Juan Carlos, orientado a alumnos con necesidades educativas especiales, donde se emplea de modo predilecto la metodología de la alfabetización visual.

De acuerdo con los postulados pedagógicos de Cossío y más recientemente planteados por la "Arts based research" de Finley (2008) o por Tilley (1991), la pedagogía como arte no es solo una propuesta estética, sino que además se trata de toda una forma de comunicación y aprendizaje a través de registros visuales, 
fotografías, imágenes, dibujos, videos o gráficos, que pueden ser producidos por los propios participantes. El empleo de estos medios audiovisuales para la educación consigue involucrar a educadores y educandos en un proyecto común, donde se genera una socialización y discusión de los conceptos jurídicos leídos en los textos y se plantea una discusión basada en algunos ejercicios de creatividad con respecto a las ideas y las imágenes que han de ser analizadas en clase y recreadas desde nuestro propio imaginario.

Estas estrategias educativas están especialmente indicadas para personas con DI o con dificultades en la comprensión y producción lingüística, pues permiten expresar significados, emociones y expresiones que difícilmente podrían ser evocadas o reproducidas con palabras. La ilustración extiende el sentido del relato, y los textos relatados buscan orientaciones que encuentran en la representación gráfica la oportunidad de una comunicación más libre y estimulante. La mayor estimulación cognitiva y el sentido de propósito y de utilidad que viene dado por este tipo de aprendizaje visual, en que los participantes construyen su imagen y su identidad, nos parece un incentivo a la creatividad por cuanto siempre se deja un margen al sujeto para oponerse o resignificar sus exigencias y derechos (Pallarès et al., 2020).

Además, nuestra experiencia ha revelado que a los estudiantes les resulta mucho más motivador este método pedagógico, que no sentarse simplemente de manera pasiva en el rol de observador que únicamente escucha una lección teórica. Sobre todo, por cuanto se trata de elaborar de manera creativa y personal un producto narrativo-visual con vídeos, fotografías o documentos gráficos que ellos mismos puedan producir e interpretar, implicándose activamente en la recogida de datos y en su confección para después compartirlos en grupo, generando nuevos significados de manera participativa, con esta metodología dialógica y democrática donde se fomenta la capacidad de escucha, visibilizando, respetando y apoyando la diversidad. 


\section{Descripción de una intervención educativa a través del "dibujo identitario" y de "Fotovoz" a partir del concepto del derecho}

Luego de haber reflexionado sobre los derechos fundamentales estudiados en clase, se realiza una tormenta de ideas donde se elabora conjuntamente una amplia lista de derechos fundamentales reconocidos en la Constitución y de sus principales instrumentos de defensa. En esta actividad se propone al estudiante que seleccione uno o varios derechos que cree que tiene, los que considere más relevantes, los que sean más significativos para él o ella en este momento, y se les pide que diseñen un dibujo rápido de elementos cotidianos en el que puedan contar una historia relacionada con ese derecho fundamental, como respuesta a la pregunta de qué significa tener ese derecho y en qué medida se cumple o no se cumple en el día a día.

Después, la profesora invita a cada estudiante a explicar el contenido de su dibujo (o, en caso de preferir otro formato, la fotografía elegida) para dar forma a su mirada personal sobre ese derecho fundamental. Para ello, se les propone que elijan tres fotografías o dibujos de "cosas que ayuden al reconocimiento de ese derecho", "cosas que no ayudan", y "propuestas de mejora". Se les pide también que incluyan una frase indicativa de su significado añadida por ellos mismos donde valoren la imagen y expliquen por qué la han elegido. A partir de estos materiales, la profesora resumirá lo que han dicho en sus textos y testimonios personales y dará paso a una lección participada, donde cada derecho se discutirá por todo el grupo con ejemplos y casos concretos a fin de identificar, comprender y reivindicar mejoras en el ejercicio de dichos derechos.

Se ofrece también a los alumnos la posibilidad de generar elementos propios con rasgos identitarios, como la posibilidad de abordar diferentes conceptos jurídicos con otro tipo de elementos que también hacen parte del alfabeto visual, como audios, vídeos, etc., que son producidos por los alumnos y que 
luego serán analizados en clase. El objetivo de implementar esta dinámica, también conocida como "Fotovoz", es generar un mayor compromiso con la lucha por los derechos humanos. Esta dinámica ha sido aplicada con éxito para favorecer la inclusión y el empoderamiento de personas con DI, al invitarles a relacionar los clásicos procesos de lectoescritura con el conocimiento visual o la alfabetidad visual (Esteban et al., 2017, p. 13).

Por ejemplo, al iniciar el curso se les ofrece la lectura de La Constitución española en lectura fácil (Plena inclusión España, 2015) o la "Convención sobre los derechos de las personas con discapacidad. Adaptada para personas que utilizan Sistemas Pictográficos de Comunicación" (CEAPT, IMSERSO, 2010), que utilizan el simbolismo por su simplicidad, y por su facilidad no solo para verse y reconocerse, sino también para recordarse y reproducirse (Huerta, 2020). Como expresa muy bien Dondis (2017), "si es cierto el adagio chino de que 'una imagen vale por mil palabras', más lo es el que 'un símbolo vale por mil imágenes'" (p. 90), por cuanto puede ofrecernos a través de la simplificación un significado más intenso y destilado.

Este lenguaje visual sirve también como punto de partida para un pensamiento creativo, que acerca al estudiante a la experiencia estética, fortaleciendo su creatividad, su capacidad de asombro y sus habilidades técnicas, desde la elaboración de ejercicios prácticos basados en la libertad de expresión. El objetivo general es aumentar el interés y la participación de los alumnos con imágenes por su potencial imaginativo para describir la realidad, pues como señala Martha Nussbaum (1997): "la luz de la imaginación poética es un agente crucial de igualdad democrática para los excluidos, pues sólo la imaginación sabrá expresar los hechos de sus vidas y ver en su tratamiento desigual la degradación de uno mismo" (p. 161). 
A este proceso creativo le acompaña una primera fase de apreciación, que comienza con el visionado de imágenes artísticas o dibujos realizados por otras personas con discapacidad, donde los estudiantes pueden ver cómo se emplea el dibujo como herramienta para sus proyectos artísticos creando imágenes o dibujos que expresan visualmente lo que las palabra callan, permitiendo una recreación mucho más ajustada de cómo se sienten con respecto, por ejemplo, al "derecho a la participación a la política" (véanse Figuras 1 y 2), que hasta hace bien poco había sido negado a las personas con discapacidad y que, gracias a la manifestación de su deseo y voluntad de votar y de hacer valer sus derechos, y gracias al trabajo y el compromiso de algunas entidades en la defensa de sus derechos, se va abriendo cada vez más la posibilidad real de que puedan participar de manera activa en procesos electorales, en partidos políticos, en asociaciones o en organizaciones no gubernamentales.
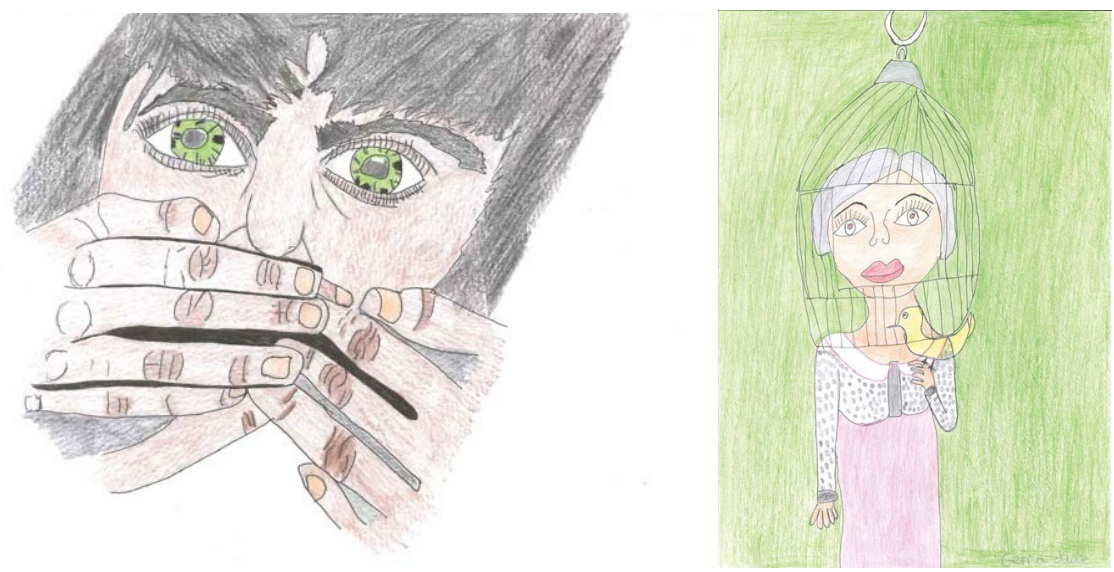

Figuras 1 y 2. Imágenes extraídas del libro de Albert et al. (2019a). 
En este caso, el dibujo se utiliza como apoyo a la narración oral para explorar las expectativas y proyectos de vida de las personas con discapacidad, con representaciones más concisas de los elementos clave de su experiencia vital. Por ejemplo, este dibujo (Figura 1) permitió a su autora proyectar con matices diversos varias dimensiones de ese derecho a la participación política, que deseaba para así, y que quizá, por las dificultades de expresión oral no podría haber sido expresado de una manera más eficaz. En efecto, no se trata de sustituir la palabra por la imagen, sino de mezclar texto e imagen y hacerlos converger de una manera sugestiva y rompedora, para que produzcan un efecto emocional que aumente nuestra sensibilidad moral hacia la opresión social o las injusticias expandiendo nuestra imaginación, conocimiento y empatía hacia los demás, y que sirva también para poner en cuestión y en el debate público estas temáticas de interés en la defensa de los derechos humanos.

Estos materiales audiovisuales contribuyeron a potenciar la participación de los estudiantes universitarios con DI, quienes discutieron y analizaron conjuntamente algunas de las situaciones que les afectan en su proceso de participación política, centrándose específicamente en las dificultades o barreras encontradas en el camino hacia el reconocimiento de sus libertades y derechos, en los obstáculos experimentados a su autonomía personal, así como algunos de los temores y preocupaciones compartidas a la hora de conseguir un trabajo o lograr emanciparse. En definitiva, los recursos audiovisuales sirvieron de punto de partida para la expresión de las dificultades que se encuentran para hacer realidad y dotar de efectividad a ese promulgado derecho a la representación política y social.

Entre otras preguntas, tenían que responder el siguiente cuestionario: ¿Qué derechos crees que están funcionando realmente en tu vida? ¿Qué cosas hay que mantener? ¿Qué cosas no están funcionando y hay que cambiar, tienen que ser diferentes o parar? ¿Sobre qué derechos hay deseo, intención o necesidad 
de ejercicio? ¿Sobre cuáles se producen situaciones de vulneración? ¿Qué derechos están más presentes en tu vida cotidiana, cuya vulneración genera un mayor malestar o indignación?

Para responder a estas preguntas se les pide que piensen en su vida profesional, en su salud, su bienestar, su participación en decisiones, en su ocio, aprendizajes, amigos, hogar, elección y control... Se mide con este ejercicio su capacidad para conectar con realidades locales y situadas, en la dilucidación de su situación social, de sus necesidades y capacidades, haciendo converger estas inquietudes sobre lo personal y lo social con lo político y lo cultural. Como recurso pedagógico y, dado que se ha mostrado que el aprendizaje en personas con DI se produce con mayor facilidad "si se apoya en signos, gestos, señales, imágenes, dibujos, gráficos, pictogramas o cualquier otro tipo de clave visual" (Araque, 2017, p. 89), se sigue la metodología de la alfabetidad visual que proporciona un mayor número de ejemplos, de ejercicios prácticos y de más ensayos y repeticiones donde puedan verse integrados contenidos teóricos con elementos gráficos y técnicas visuales que les ayuden a concretar las cuestiones o temas más relevantes de su discurso.

La idea es que puedan elaborar una "Carta de Derechos" adaptada a las condiciones interrelacionadas en las que la persona vive su día día, y las consecuencias prácticas de los derechos humanos en su vida cotidiana, calibrando no solo el impacto que esta actividad tiene en la vida de la persona, sino también el impacto social de dichos derechos en su entorno social inmediato, en el vecindario, en la comunidad o las organizaciones educativas o de apoyos de los que se sirva, para lo cual es necesario estudiar también la posibilidad de buscar soluciones más amplias, que abarquen los patrones globales socioculturales, y que midan la influencia que tienen en la configuración sociopolítica del país, para abrir y llevar a cabo cambios para que sus derechos no se vean vulnerados. Se espera que este ejercicio práctico 
sirva como conclusión de lo aprendido en la asignatura de "Introducción al Derecho" y, al mismo tiempo, sea un punto de partida para facilitar y mejorar el ejercicio de derechos. Se trata, pues, de explorar las formas en que las personas con DI puedan intensificar su capacidad de agencia y de decisión.

Gracias a la metodología del recurso visual del "dibujo identitario" la respuesta a este cuestionario tuvo un aspecto muy positivo por cuanto los materiales audiovisuales utilizados, señeramente el dibujo, son un producto y, al mismo tiempo, son un proceso. Es decir, que:

(...) mientras la persona dibuja está construyendo conocimiento y significados sobre sí misma, así como sobre el dibujo. Conocer cómo se construye el dibujo nos informa sobre cómo la persona se ve a sí misma y ve el mundo en un lugar y un momento determinados. Lo que nos lleva a sugerir que artefactos como los dibujos, u otros sistemas de representación externa, pueden llegar a tener una función epistémica al convertirse en un medio de pensamiento, aprendizaje e incluso cambio cognitivo (Esteban et al., 2017, p. 3).

Así, hallamos un buen ejemplo en la utilización de métodos visuales por jóvenes con discapacidad intelectual en la expresión de lo que ellos consideraban que era su derecho a una educación inclusiva (Figuras 3 y 4). 


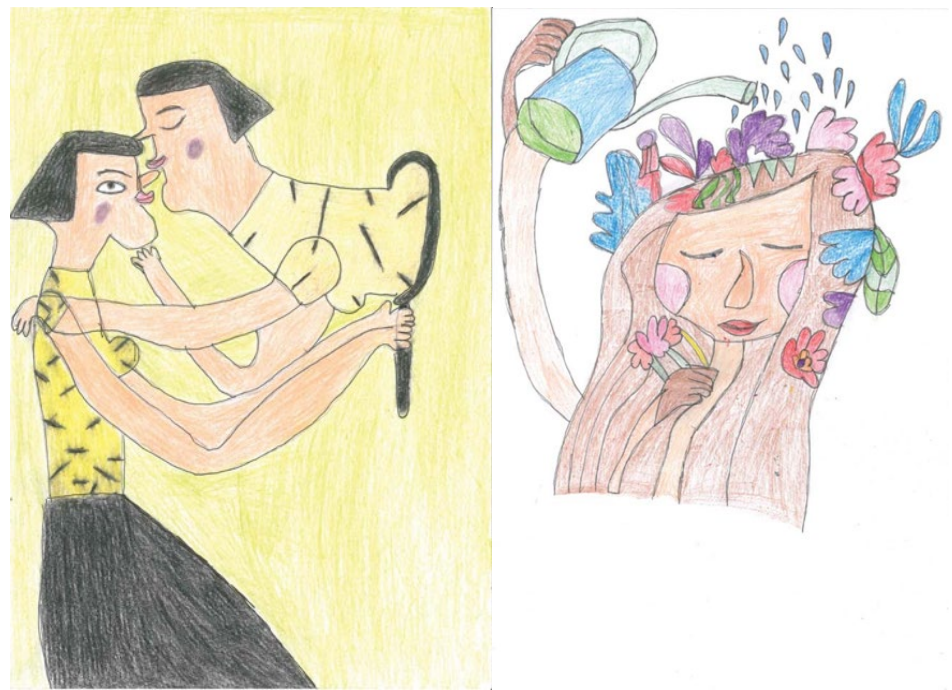

Figuras 3 y 4. Imágenes extraídas del libro de Albert et al. (2019b).

A través del dibujo, el estudiante se convierte en un partícipe activo del hecho de la comunicación y de la interpretación del contenido producido, otorgando significación a las imágenes y a las palabras que ha articulado en la narración de sus vivencias y puntos de vista, y que luego han sido analizados en grupo, fomentando una atención mayor y más imaginativa hacia las palabras, hacia los textos completos y hacia la inherente y productiva ambigüedad del lenguaje en relación con las imágenes, con referencias a la cultura y al marco semántico y social en que se inscriben esos recursos gráfico-visuales, hasta el punto de generar nuevos significados y convertirse en el inicio de un nuevo relato escrito y oral argumentado.

El objetivo es crear conciencia social sobre los abusos del pasado, aportando una dimensión est(ética), es decir, artística y moral, a través de un arte 
comprometido que sirva para promover, de modo responsable, los derechos humanos. A este respecto, se ha tratado de mejorar la calidad y el principio de igualdad de oportunidades ofrecido por nuestros sistemas educativos, declarando la necesidad de que el alumnado con discapacidad participe en la vida universitaria en igualdad de condiciones que el resto de sus compañeros. El objetivo final es, pues, vencer esta situación de impotencia derivada de las barreras ambientales, para que puedan adquirir el control sobre sus propias vidas, algo que afecta a otras facetas importantísimas dentro del proceso educativo como la formación en valores y la autoestima de los estudiantes, que ven reforzado su papel en la sociedad y fortalecida la seguridad en sí mismos gracias a formar parte activa de los programas educativos de los que son destinatarios (Cárdenas et al., 2017).

\section{Resultados: el proyecto de innovación docente "Discapacidad: Una cuestión de derecho" y las Guías de Derechos}

A continuación, y como una manera de evidenciar los progresos que han hecho los estudiantes en sus experiencias con la imagen en el curso, describiremos los principales resultados y actividades realizadas en el marco del proyecto de innovación docente "Discapacidad: Una cuestión de derecho", desarrollado gracias a una ayuda obtenida en una convocatoria de competencia pública de la Oficina de Derechos Humanos de la Universidad Rey Juan Carlos.

Dicho proyecto se encamina a la formación, conciencia y sensibilización de la sociedad y de los miembros de la comunidad universitaria en relación con los derechos de una minoría en situación de vulnerabilidad, las personas con DI. El objetivo fundamental del proyecto ha sido sensibilizar a la comunidad universitaria y a la sociedad en general sobre los derechos de las personas con DI. Un aspecto vital de esta tarea ha sido empoderar a las personas con DI para que exijan lo que debería estar garantizado por derecho: su libertad, su 
derecho a la igualdad y a la dignidad. Para ello, era necesario conocer y tener muy presente su opinión, la voz de los propios alumnos, que se convirtieron en protagonistas de las acciones formativas y divulgativas diseñadas para cumplir este fin.

A tal efecto, se organizaron unos seminarios de trabajo cooperativo entre los alumnos URJC y los alumnos Esfera, y se organizaron dos talleres en la Semana de la Ciencia de 2019. Los talleres fueron titulados "Te enseño mis derechos" y, de acuerdo con este lema, fueron liderados por los propios jóvenes con DI participantes en el proyecto'. El hecho de que fueran ellos mismos quienes, en primera persona, expusieran cuáles son sus derechos, tanto a sus iguales (centros ocupacionales, asociaciones o fundaciones) como a través de acciones de sensibilización dirigidas a colectivos diversos (entre los que se encuentran los estudiantes, los entornos sanitarios y los profesionales del derecho), creemos que posee un alcance que contribuye enormemente a la inclusión social del colectivo, por cuanto ofrece una nueva oportunidad de aprendizaje para desarrollar habilidades cognitivas y funcionales, ampliar recursos emocionales y disfrutar de la experiencia, fortaleciendo la seguridad y la autoestima en sí mismos ante la capacidad de formar parte activa del programa.

Fruto de dichos talleres, se confeccionaron y publicaron dos guías: la Guía de derechos de participación política y social (Albert et al., 2019a) y la Guía de derechos en el ámbito de la salud (Albert et al., 2019b), en formato de lectura fácil, sobre los derechos de las personas con DI, donde el arte y la educación artística jugaron un papel esencial para la transformación y acción social en este contexto, porque los participantes pudieron apreciar y producir arte visual,

'Véase un video resumen del evento: https://www.youtube.com/watch?v=xej7NMd_250 y algunas noticias en diversos medios de comunicación que hicieron eco del evento: http://www.aldialeganes.es/noticias/leganes-local/3676/fundacion-esfera-y-la-urjcelaboran-lasprimeras-guias-de-derechos-para-personas-con-discapacidad-/ 
mediante un programa bien estructurado y apropiado a las necesidades de cada alumno, donde se representaban los derechos fundamentales en lectura fácil con el acompañamiento de imágenes y dibujos para generar espacios de reflexión alrededor del tema de la imagen, con el fin de desarrollar la creatividad y fomentar la capacidad del visual de las personas con DI, contribuyendo así al fortalecimiento de su alfabetidad visual.

\section{Creación del Título universitario de "Asistente Jurídico" para personas con DI}

La experiencia de este proyecto de innovación docente fue tan positiva que ha inspirado la creación de un Título de Extensión Universitaria que comenzó a impartirse en enero de 2021 en la URJC. Se trata de un Título de "Asistente Jurídico" cuyo objetivo es que las personas con DI adquieran una cualificación jurídica específica para acceder al entorno laboral y trabajar como personal de apoyo en las tareas propias de un despacho de abogados o asesorías, como asistentes jurídicos en consultoría, o incluso como divulgadores y formadores en derecho.

Este título específico en derecho se oferta por primera vez en el entorno universitario este año académico 2020-2021, y constituye una oportunidad para que las personas con DI puedan elegir esta formación como alternativa diferente a los roles que habitualmente se les asigna en el mercado laboral.

Por esta razón, el título se propuso como objetivo motivar a los jóvenes que cursan secundaria para que continúen su formación universitaria, con el fin de que poco a poco se opere la normalización de la presencia de personas con DI en el ámbito universitario y de que la sociedad tome mayor conciencia de la necesidad de ofrecer apoyo para una plena integración psicosocial de este colectivo en el entorno laboral, más aún, en ámbitos laborales que están fuertemente tecnificados, como el ámbito jurídico, donde la comprensión 
de los textos jurídicos no siempre es fácil, a pesar de que la accesibilidad a sus contenidos debe constituir un derecho para todo ciudadano con o sin discapacidad.

En relación con la marcada —incluso deliberada - opacidad del lenguaje jurídico, cabe destacar tres elementos (retórica, burocracia y violencia) que son los que, según Boaventura de Sousa Santos, moverían el mundo y determinarían la teoría y la praxis jurídica. De Sousa (2018) aclara además que esos tres componentes estructurales se interpenetran de manera que, por ejemplo en el Estado moderno, la retórica no solo se reduce cuantitativamente sino que ha sido contaminada o infiltrada cualitativamente por la burocracia y la violencia dominantes: "En realidad, la tendencia secular (de los últimos 200 años) se ha orientado hacia una retracción gradual de la retórica y una expansión gradual de la burocracia y de la violencia" (p. 201). Esto explica que los discursos jurídicos del siglo XXI no se parezcan a los de Cicerón, sino a los de la burocracia, lo cual implica ciertamente, según De Sousa, convertir los discursos jurídicos en cuanto productos burocráticos, en instrumentos de violencia o formas de dominación que acontecen en todas las escalas del derecho, al hacerse su lenguaje poco o nada accesible para la ciudadanía en general, y constituir de facto un muro infranqueable para colectivos vulnerables de la sociedad. ¿Cómo cohonestar la propia naturaleza ininteligible de determinados textos jurídicos y, al mismo tiempo, la necesidad de hacer cognoscibles y enseñables estos derechos y deberes a toda la ciudadanía, especialmente a aquellos colectivos más vulnerables? Esta problemática inició y motivó la creación de una metodología y una didáctica del derecho, que estuvieran ligadas a una educación con vocación transformadora, para lo cual era preciso implementar una pedagogía de la imagen y de la alfabetidad visual basada en una aproximación democratizadora del derecho².

\footnotetext{
${ }^{2}$ Una muestra de este ejercicio pedagógico y socializador del derecho fue la elaboración del libro Guía de derechos en el marco de la crisis de la COVID 19 (Albert et al., 2020) en lectura fácil, cuyo propósito era ofrecer información útil y sencilla a la ciudadanía sobre las ayudas que les corresponden, con datos prácticos e infografías y con consejos sobre prevención.
} 
Siguiendo a Paulo Freire (1997) en su aseveración de que "enseñar no es transferir conocimiento, sino crear las posibilidades de su producción o de su construcción" (p. 24), resulta cada vez más necesario generar procesos de enseñanza-aprendizaje capaces de implicar a los estudiantes, darles protagonismo y conseguir que lo que aprendan sea realmente significativo. De acuerdo con este principio, se consideró oportuno proporcionar herramientas innovadoras que posibilitaran la superación de barreras en el aprendizaje, razón por la cual los contenidos docentes del Título de Asistente Jurídico se elaboraron según el diseño facilitado por la Fundación Esfera, con revisión oficial de Lectura Fácil, también se proporcionó un ordenador con una programación de software especial a cada uno de los alumnos del Título, en el convencimiento de que la irrupción en las aulas de las tecnologías de la información y las comunicaciones (TIC) puede "llegar a cumplir una función de rampa" (Arrieta, 2019, p 121) por cuanto representa un instrumento enriquecedor para los procesos formativos dirigidos a jóvenes y adultos con discapacidad. En este caso, se utilizaron por su capacidad para incrementar la atención, la motivación y las destrezas relacionadas con el diseño visual y la alfabetización visual (Pagliarulo, 2013, pp. 105-116), para establecer puentes de comunicación que favorezcan su desarrollo pleno y mejoren la calidad de vida de este colectivo, al brindar soluciones ante barreras de aprendizaje y participación. Conscientes de la influencia de la alfabetización visual en los procesos de enseñanza y aprendizaje de las personas con DI, se emplearon las TIC a través de herramientas visuales como recurso metodológico, con el fin de dar una orientación más práctica y aplicada a la intervención educativa.

Para los estudiantes con DI el proyecto representó una mejora significativa en su vida cotidiana, y puso de manifiesto que la ciudadanía solo puede ejercerse desde el conocimiento y la conciencia de la titularidad de los derechos, con una pedagogía inclusiva que los haga cognoscible de, por y para ellos. Por eso pensamos que la accesibilidad cognitiva, el derecho a entender y ser entendido, 
cuando se trata de derechos, es una exigencia básica del Estado de Derecho. Si la educación en derechos humanos es un asunto de interés público, esta debe abordarse colectivamente como cosa pública, en situaciones participativas y prácticas pedagógicas construidas de manera accesible para todos, donde se puedan explorar los potenciales democratizadores de las prácticas mediáticas para el ámbito educativo y social.

\section{Conclusiones}

La alfabetización visual como instrumento eficaz para la adquisición de contenidos relacionados con el derecho por parte de personas con discapacidad, se ha considerado como la metodología y la herramienta de cambio más eficaz para dar respuesta a los alumnos con necesidades educativas especiales, para promover el pensamiento inductivo y la capacidad de establecer conexiones y relaciones críticas entre los mensajes visuales y la intencionalidad de la imagen, buscando así el desarrollo de un pensamiento divergente y de la creatividad. Sin embargo, no ha de olvidarse que el éxito de esta metodología depende también de los valores operativos en la educación ambiental y en su entorno social, y que la pedagogía social empieza por nosotros, los ciudadanos y los juristas, pues:

(...) la discriminación secular que sufren estos ciudadanos no es un problema individual debido a su inadaptación al entorno, sino que es causado esencialmente por el prejuicio o desvalor inmanente en la sociedad española, que los considera inferiores o incapacitados para desenvolverse eficazmente en las relaciones sociales. (Álvarez, 2019, p. 25)

Es necesario desarrollar una pedagogía que sensibilice a la sociedad en cuanto a los deberes de respeto y solidaridad para con las personas con DI, si de verdad se quiere asumir la carga de la realización efectiva de sus derechos. Por ejemplo, haciendo notar que el lenguaje jurídico y las imágenes que utilizamos en derecho no son ideológicamente neutras, sino que contienen 
un gran poder persuasivo porque proyectan y definen la imagen pública de las personas con discapacidad, de modo que pueden ser empleadas para acentuar la discriminación o favorecer la inclusión. Debemos, pues, preocuparnos también de poner de relieve "el orden ideológico que condiciona estas formas de lectura, que determinan cuáles son los sujetos y los lugares sociales donde es legítimo mirar y de cuáles es normativo apartar la mirada" (Martínez y Carrión, 2019, p. 82).

Se necesita hacer una gran pedagogía social, y para ello es preciso cuestionar nuestros (pre)juicios y creencias y contribuir, en última instancia, a ayudarnos a plantear reformas de leyes o prácticas legales injustas. Por ello ha sido importante ofrecer espacios de comunicación y expresión más abiertos donde se dé voz a los protagonistas de esta acción educativa, que se les facilitasen recursos visuales y herramientas como dibujos o fotografías que les permitieran expresar sus vivencias con sus propias palabras, puesto que nadie mejor que ellos puede hablar de las barreras y las dificultades que se encuentran en la realización de sus derechos.

Las imágenes les han permitido construir también conocimiento a partir de sus experiencias concretas, de pequeñas historias de vida o microrrelatos donde se entretejen elementos narrativos con una gran fuerza expresiva que permite representar en la obra visual lo que a veces tienen guardado o reprimido en el subconsciente, ofreciéndoles así una vía de salida y de comunicación para dar visibilidad a esos territorios personales, y que puedan experimentarlos, recordarlos, transformarlos, simbolizarlos o incluso transgredirlos.

Son estas miradas, estos relatos de los derechos desde dentro, las que deberían tenerse en cuenta en la definición, formulación e implementación de una política pública que realmente tenga en cuenta cómo se sienten las personas con DI ante las diferentes barreras sociales y actitudinales. Es preciso, 
pues, un marco legislativo que no prescinda de las propias percepciones, valoraciones y actitudes de las personas afectadas, de los actores y de los grupos sociales que han sido a menudo invisibilizados, y que deben ser tenidos en cuenta para elaborar sus propias mediaciones, como portadoras y generadoras también de valor cultural y simbólico, con agencia individual y colectiva para plantear un horizonte de cambio y de emancipación social (Espín y Mera, 2019, p. 36). Son sus derechos, y tiene todo el sentido que las propuestas de cambio provengan de los testimonios de quienes lo viven en primera persona, dotándose de narrativas propias, dándose sus propias imágenes, con otros significados profundos ligados a las realidades sociales de las comunidades que desean comunicar. De esta manera, la historia colectiva del derecho se transforma en una historia personal que, al mismo tiempo, posibilita el cambio en cuanto que es también construcción social y narrativa. Por resumir esta demanda de reconocimiento en tres palabras, se trata de dotarles de: visibilidad, voz y sentido.

A partir de los promisorios resultados que hemos obtenido en esta intervención educativa, nos parece importante seguir indagando en futuros estudios y proyectos que exploren estos aspectos comunicativos audiovisuales que permitan la mejora del diseño de los programas académicos, donde se cuiden y promuevan aspectos educativos que faciliten el aprendizaje y la comunicación de los jóvenes que viven a diario con una discapacidad.

Otra cuestión interesante que consideramos oportuno subrayar es que esta metodología inclusiva y la propuesta pedagógica que se diseñó para esta intervención educativa se pueden aplicar con éxito en cualquier programa académico de educación formal universitaria que se proponga como objetivo resaltar la importancia de la alfabetización visual y del aprendizaje de conceptos básicos a través de la imagen y el manejo de medios estéticos y artísticos para desarrollar su capacidad creativa y de análisis, y para proporcionar una visión 
más holística, propositiva, inclusiva y omnicomprensiva de las realidades y experiencias o problemas vitales que nos acucian como sociedad.

En definitiva, la enseñanza formal del derecho en personas con discapacidad intelectual en el marco de este título universitario, ha representado además una experiencia formativa única también para los docentes implicados, y ha supuesto un punto de partida con el que se espera seguir contribuyendo a la formación docente y a una visión del programa curricular mucho más enriquecedora desde el ejercicio crítico de la alfabetización visual, que se promueve desde políticas inclusivas que facilitan la generación de opiniones y visiones que han sido históricamente silenciadas, con unas herramientas que ofrecen espacios de comunicación y expresión más abiertas, y menos rígidas que las que habitualmente se solía ofrecer en la docencia reglada mediante cuestionarios o exámenes convencionales que apenas lograban medir la capacidad memorística del educando, obviando otras muchas otras capacidades creativas que convierten la experiencia didáctica en un espacio capaz de transformar la representación que se hace de las propias vivencias del educando, y que es capaz de cambiar y mejorar, no solo el entorno académico o universitario, sino también el entorno social.

\section{Referencias}

Albert, M., Manzanero, D., López, M., Trigo, C., Ricote, E., López, M. y López, C. (2019a). Discapacidad intelectual: una cuestión de derecho. Guía de derechos de participación política y social. Universidad Rey Juan Carlos. https://burjcdigital.urjc.es/handle/10115/16573

Albert, M., Manzanero, D., López, M., Trigo, C., Ricote, E., López, M. y López, C. (2019b). Discapacidad intelectual: una cuestión de derecho. Guía de derechos en el ámbito de la salud. Universidad Rey Juan Carlos. https://eciencia.urjc.es/handle/10115/16572

Albert, M., Manzanero, D. y Lorca, V. (2020). Guía de derechos en el marco de la crisis de la COVID 19. Universidad Rey Juan Carlos. 
Álvarez, H. (2019). La dimensión constitucional de la capacidad jurídica de las personas con discapacidad. En J. Morcillo (Dir.), Discapacidad Intelectual y Capacidad de Obrar. De la sustitución de la voluntad al apoyo en la toma de decisiones. Tirant Lo Blanch.

Araque, J. M. (2017). Alfabetización visual: diseño de una intervención para la educación en valores en población con discapacidad intelectual. En S. Carrascal e I. Ceballos (Coords.), 12 Miradas: perspectivas actuales en educación, arte y sociedad. Editorial Universitas.

Arrieta, A. (2019). TIC dirigidas a la superación de barreras educativas de las personas con discapacidad. Innovaciones educativas, 21 (31), 115-130.

Belda, E. (2019). Dignidad y discapacidad. Una perspectiva desde los derechos humanos. Tirant Lo Blanch.

Cárdenas, R., Barriga, A. P. y Lizama, J. I. (2017). La expresión artística como estrategia didáctica para el desarrollo de la afectividad y la autoestima en una persona con Discapacidad Intelectual y Síndrome Alcohólico Fetal (SAF). Arte, individuo y sociedad, 29, 205-222.

CEAPT, IMSERSO. (2010). Convención sobre los derechos de las personas con discapacidad. Adaptada para personas que utilizan Sistemas Pictográficos de Comunicación. https:// www.plenainclusion.org/informate/publicaciones/convencion-sobre-los-derechos-de-laspersonas-con-discapacidad-adaptada-para

Cossío, M. B. (1906). El maestro, la escuela y el material de enseñanza. BILE, XXX, tomo II, 258265, 346-ss.

Cossío, M. B. (1966). De su Jornada (2a ed.). Aguilar.

De Sousa, B. (2018). Construyendo las epistemologías del sur: para un pensamiento alternativo de alternativas ( $1^{\text {a }}$ ed.). (Compilado por M. P. Meneses et al.). Ciudad Autónoma de Buenos Aires.

Dondis, D. A. (2017). La anatomía del lenguaje visual. En La sintaxis de la imagen. Introducción al alfabeto visual (J. González, traduc.) (1ª ed. 1973, Reedición revisada). Editorial Gustavo Gili.

Espín, A. y Mera, M. (2019). La Inclusión desde un enfoque de Derechos Humanos en estudiantes con Necesidades Educativas Especiales Asociadas o no a una Discapacidad. Revista Publicando, 6(21), 34-47.

Esteban, M., Pallisera, M., Fullana, J. y Gifre, M. (2017). Más allá de la palabra escrita. La utilización de recursos visuales como estrategia metodológica en ciencias sociales y de la educación. Revista Electrónica de Metodología Aplicada, 22(1), 1-22. 
Finley, S. (2008). Arts based research. In J. G. Knowles \& A. L. Cole (Eds.), Handbook of the arts in qualitative research: Perspectives, methodologies, examples, and issues. Sage.

Freire, P. (1997). Pedagogía de la autonomía. Saberes necesarios para la práctica educativa. Siglo XXI.

Foucault, M. (1996). La verdad y las formas jurídicas. Editorial Gedisa.

Huerta, R. (2020). El diseño de letras como entorno visual para educar en diversidad. Artseduca, $25,5-22$.

Martínez, S., \& Carrión, E. (2019). Participatory video and visual literacy: Challenges and opportunities for social and educational change. Obra digital: revista de comunicación, $17,77-91$.

Nussbaum, M. (1997). Justicia poética. La imaginación literaria y la vida pública. Editorial Andrés Bello.

Otero, E. (1994). Manuel Bartolomé Cossío: pensamiento pedagógico y acción educativa. Centro de Publicaciones del Ministerio de Educación y Ciencia.

Pagliarulo, E. (2013). La importancia de la 'alfabetidad visual' en la formación docente. En VV.AA., Actas del Congreso Iberoamericano de las Lenguas en la Educación: las lenguas en la educación, cine, literatura, redes y nuevas tecnologías (pp. 105-116).

Pallarés, M., Villalobos, J. V., Hernández, J. D., Cabero, I. (2020). Pedagogía con carácter: aproximación a la disciplina pedagógica como campo de reflexión del sujeto de la educación a partir de Ricoeur. Bajo Palabra. Revista de Filosofía, 24, 525-546. https://doi. org/10.15366/bp.2020.24.026

Plena inclusión España. (2015). La Constitución española en lectura fácil. https://www. plenainclusion.org/informate/publicaciones/la-constitucion-espanola-en-lectura-facil

Suriá, R., Rosser, A. y Villegas, E. (2016). Universidad y discapacidad: expectativas laborales y autoimagen entre los universitarios. Psicología y educación: presente y futuro, 2564-2571.

Tilley, P. (1991). El arte en la educación especial. CEAC.

Cómo citar: Manzanero, D. (2022). La importancia de la alfabetidad visual en la enseñanza del derecho a personas con discapacidad intelectual: una intervención pedagógica. Revista KEPES, 19(25), 165-190. https://doi.org/10.17151/kepes.2022.19.25.7 